\title{
Study of Initiation of Arc Discharges by Opening Initially Closed Electrodes
}

\author{
A. P. Glinov, A. P. Golovin, P. V. Kozlov \\ Institute of Mechanics, Lomonosov Moscow State University, \\ Moscow, 119192, Russia \\ krestytroitsk@mail.ru
}

\begin{abstract}
This work is devoted to extended arc discharges in an open-air environment between graphite electrodes. The main goal of this work is to obtain data on changes in the parameters of electric arc plasma during the initiation and development of the discharge. High-speed video recording of the discharge gap was used, synchronized with current and voltage oscillography data. Pyrometric measurements of the electrode temperature and spectral measurements of the discharge plasma characteristics in the arc column and near the electrodes were performed.
\end{abstract}

Keywords: porous electrodes, electric arc, discharge initiation, low-temperature plasma, spectrograms.

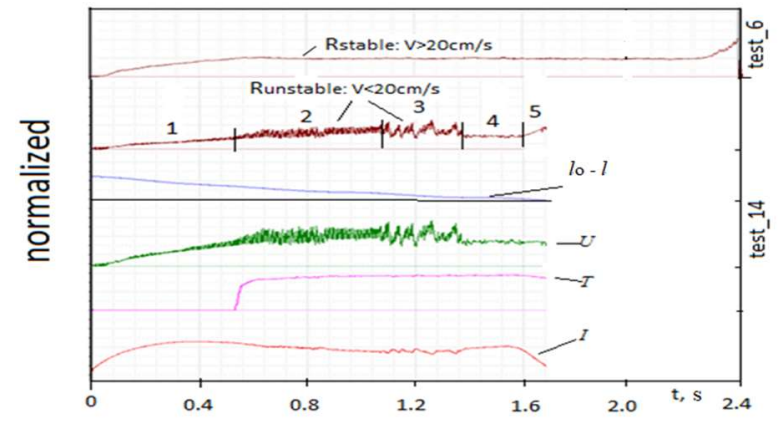

Waveforms of interelectrode gap $\left(l_{0}-l\right)$, arc column resistance $(R)$, anode temperature $(T)$, voltage $(U)$ and discharge current $(I)$
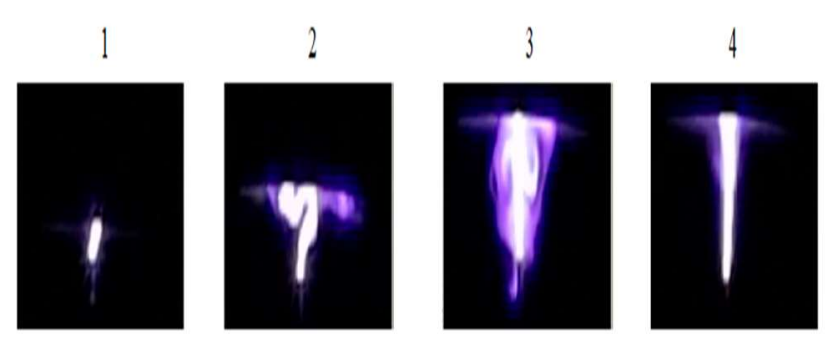

Video frame

1 - stable arc formation zone; 2,3 - zones of high-frequency (kHz-s) and low - frequency (tens of $\mathrm{Hz}$ ) instability; 4 - stable discharge, 5 - shutdown

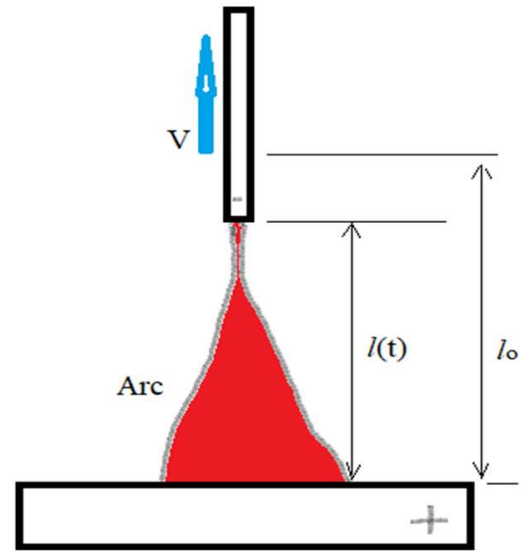

Discharge pattern

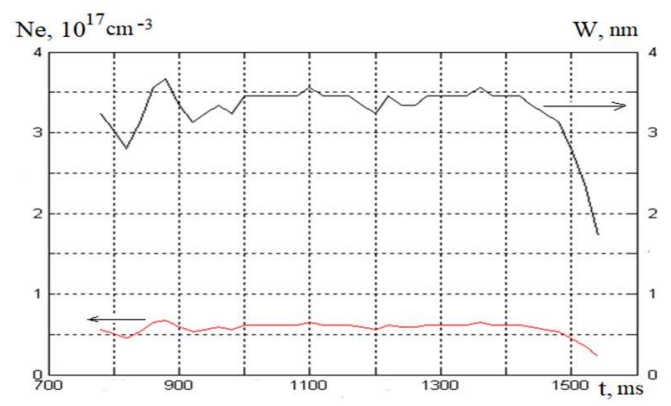

Electron concentration $(\mathrm{Ne})$ in the middle part of the column and the width (W) of the half-height of the Stark distribution pulses 


\title{
Изучение инициирования дуговых разрядов размыканием первоначально замкнутых электродов
}

\author{
А. П. Глинов, А. П. Головин, П. В. Козлов \\ НИИ Механики Московского государственного университета им. М.В. Ломоносова, \\ Россия, Москва, 119192, Мичуринский проспект, 1 \\ krestytroitsk@mail.ru
}

\begin{abstract}
Аннотация
Работа посвящена протяженным дуговым разрядам в открытой воздушной среде между графитовыми электродами. Основная цель работы - получение данных об изменении параметров электродуговой плазмы в процессе инициирования и развития разряда. Применялась высокоскоростная видео регистрация разрядного промежутка, синхронизированная с данными осцилографирования тока и напряжения. Проводились пирометрические измерения температуры электродов и спектральные измерения характеристик разрядной плазмы в столбе дуги и вблизи электродов.
\end{abstract}

Ключевые слова: пористые электроды, электрическая дуга, инициирование разряда, низкотемпературная плазма, эмиссионные спектры.

\section{1. Введение}

Главная цель проводимых исследований - изучение неустойчивостей дугового разряда и отработка способов их стабилизации. Одной из технических проблем при экспериментальном изучении протяженных (несколько см и более) дуг является проблема стабильного инициирования разряда и обеспечение минимальных помех на измерительные цепи. В частности, при инициировании разряда в воздушной среде атмосферного давления при межэлектродных расстояниях 15 $\div 18$ мм требовались (как отмечалось в [1]) высокие, более 50 кВ, напряжения осциллятора. Поэтому при изучении протяженных электрических дуг на разрядной установке НИИ механики МГУ применяется инициация разряда посредством смыкания электродов с последующим их раздвижением до выбранного межэлектродного расстояния. Система инициирования разряда [1] обеспечивала раздвижение электродов в малом диапазоне скоростей порядка $200 \mathrm{~mm} /$ с и отличалась недостаточной стабильностью работы. В настоящее время на установке П-2000 [2-4] разработан стенд для получения протяженной (вплоть до полуметра) электродуговой плазмы, образующейся при инициировании квазистационарной воздушной дуги атмосферного давления при разных режимах раздвижки электродов, в частности, создано и испытано устройство раздвижки электродов при разных $(40 \div 400 \mathrm{~mm} / \mathrm{c})$ скоростях [5]. Подготовлены модули и для более быстрых систем инициирования разряда на основе разведения первоначально сомкнутых электродов. Стабильность работы таких систем повышена за счет как подбора нагрузочных балансов, так и - выбора управляющего напряжения на электродвигателе системы раздвижки. Развита система диагностики: межэлектродного зазора, трех компонент вектора индукции магнитного поля, тока дуги и напряжения межэлектродного зазора, температуры электродов. Визуализация разряда осуществляется с помощью проведения высокоскоростной $(1200 \div 4000$ кадр/с) панорамной видеосъемки разрядного промежутка. Регистрации межэлектродного зазора обеспечивается 
на основе оцифровки показаний потенциометра (с точностью до долей мм), связанного тросом системой раздвижки. Для регистрации компонент вектора индукции магнитного поля был разработан измерительный зонд на основе созданной сборки трех взаимно перпендикулярных пластин-датчиков Холла типа Honeywellss495A1. На новом стенде проведено экспериментальное исследование протяженных (вплоть до 40 см) дуговых разрядов в свободной воздушной атмосфере между графитовыми электродами - стержневым катодом и массивными анодами. Разрядные токи - до 700 А. Показано, что оптимизация режимов раздвижки электродов и согласование электродных узлов позволяет получать стабильное горение протяженных электрических дуг в открытой воздушной атмосфере вплоть до 30 см.

Существенной особенностью данной работы является изучение спектральных характеристик межэлектродной плазмы при инициировании дуги разведением электродов с дозвуковыми скоростями. Спектральные характеристики разрядной плазмы существенно зависят от силы тока, межэлектродной среды, материалов электродов и стенок изоляторов. Эти характеристики для высокочастотных сильноточных (десятки кА) дуг в воздушной среде между металлическими (медь, алюминий) электродами изучены в [6]. Ранее спектральные исследования излучения свободно горящей дуги между стержневыми графитовыми электродами в атмосфере воздуха проводились в [7]. Были выявлены основные излучающие компоненты и зоны разряда, из которых они излучают. Определен характерный размер зоны проводимости разряда и концентрации электронов. Из анализа полученных спектров определено, что основной энергетический вклад в излучение разряда обусловлен излучением молекулы CN. Однако изучения влияния именно режимов инициирования разряда на параметры и состав разрядной плазмы не проводилось.

В настоящей работе удалось получить новые данные о влиянии скорости раздвижки электродов на режимы горения электрической дуги на графитовых электродах в воздушной среде и спектральные характеристики разрядной плазмы при разных скоростях электродов.

\section{2. Постановка работы и ключевые результаты}

При изучении протяженных электрических дуг на электроразрядной установке НИИ механики МГУ применяется инициация разряда посредством смыкания электродов с последующим их раздвижением до выбранного межэлектродного расстояния $l_{0}$. Характерное время раздвижки электродов составляет в экспериментах $0.1 \div 0.2$ с. Общая схема регистрации видеоизображений разряда и температуры электродов представлена на рис. 1 , а инициирования - рис. 2. Синхронно снимались и осциллограммы тока $I(t)$ и напряжения $U(t)$ (где $t$ - время) на разрядном промежутке. Проведены серии измерений: первая - с анодами с соизмеримыми катоду размерами $\varnothing=15$ мм; вторая - с массивными анодами, многократно превосходящими по размерам катод. Материал электродов графит 3ОПГ.

Эксперименты с дугами на соизмеримых графитовых стержневых электродах показали, что форма дуги (при квазистационарных режимах ее питания) весьма нестационарная и неединственная [1]. Соответственно и картина течения межэлектродной среды (особенно при размыкании электродов) достаточно сложная, включающая динамику дугового столба, электродных факелов и опорных пятен.

Оказалось, что традиционные способы стабилизации дуг как с помощью аксиального внешнего магнитного поля соленоида, так и квазиазимутального поля стержневой магнитной системы (MC) работают при умеренных полях, но при превышении магнитным полем критической величины развивается винтовая неустойчивость разряда. В наших экспериментах использование рассмотренных МС позволило получить стабильное горение открытых вертикальных воздушных дуг до межэлектродных зазоров порядка 15 см. Дальнейшее увеличение протяженности стабильной дуги было связано с применением массивных анодов. 


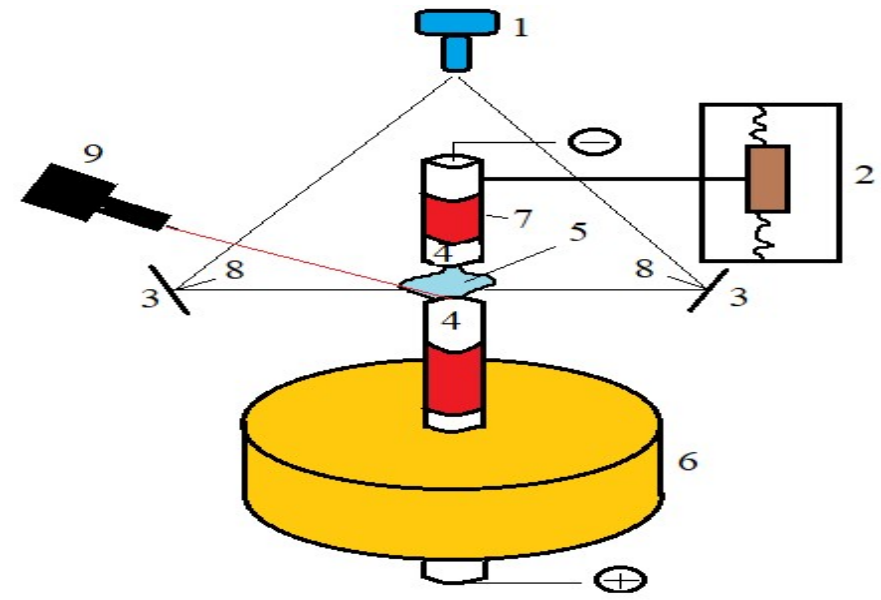

Рис. 1. Схема установки: 1 - видеокамера, 2 - механизм раздвижки электродов, 3 - зеркала, 4 - электроды, 5 - дуга, 6 - изоляционная подставка, 7 - крепежные зажимы, 8 нормали к зеркальным поверхностям, 9 - пирометр

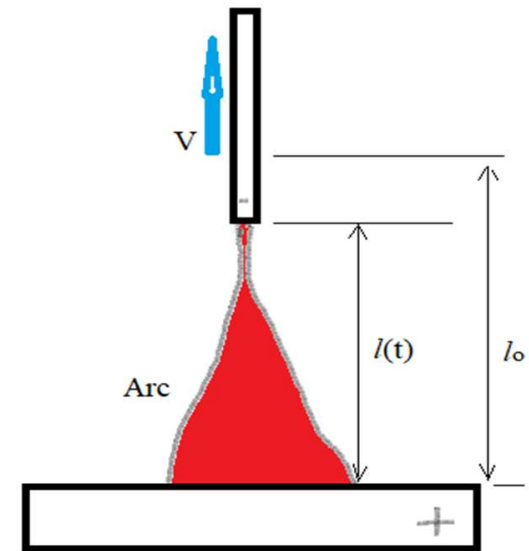

Рис. 2. Картина инициирования разряда

Проведены сравнительные эксперименты протяженного дугового разряда на массивных анодах при различных скоростях раздвижения электродов (рис. 3). Рассмотрены два регулярных режима раздвижки электродов: достаточно быстрый $(a, 2)$ и медленный $(\sigma, \varepsilon)$ режим.
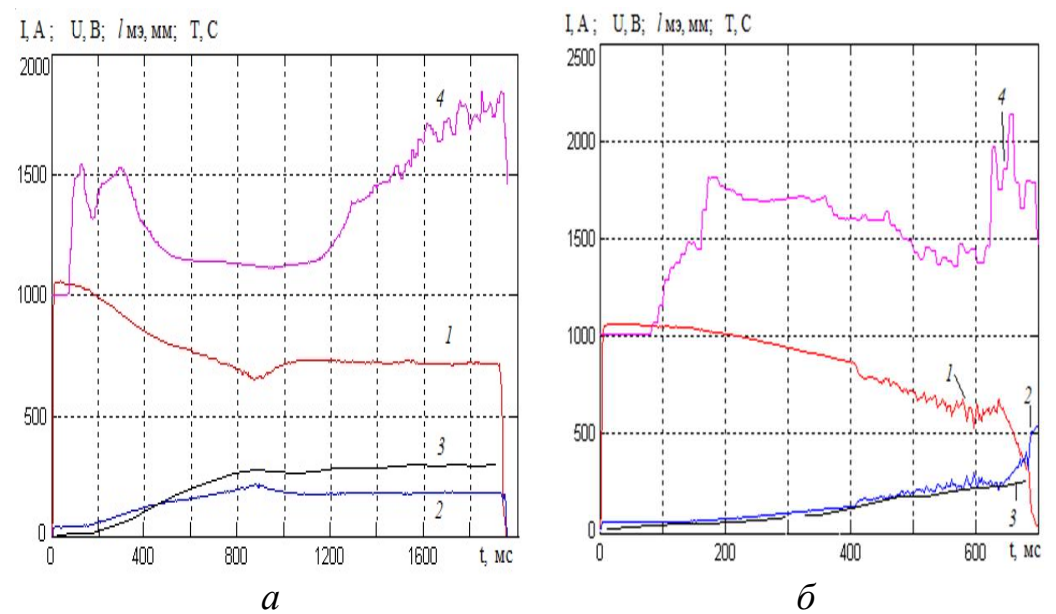

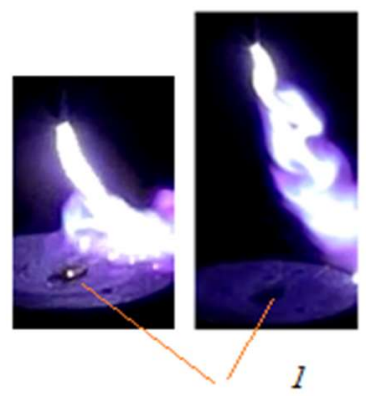

в

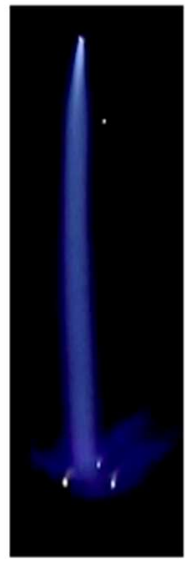

2

Рис. 3. Влияние скорости размыкания электродов на стабильность разряда: $(a, \sigma)$ - осциллограммы тока (1), напряжения (2), межэлектродного зазора (3) и температуры анода (4); ( 8,2$)$ - типичные видеокадры разряда на массивном аноде при несколько заторможенном (в) и достаточно быстром (2) размыкании электродов; межэлектродный зазор - 300 мм (2), 112 и 212 мм (в) соответственно, 1 - зона наибольшего разрушения анода из-за задержки размыкания электродов; $f_{\text {per }}=1200 \mathrm{\kappa} / \mathrm{c}$; анод - массивный в виде чаши ( $\varnothing 150$ мм) [2-4]

Первый из них $(a, 2)$ позволил получить стабильный разряд на зазоре в 30 см. Этот размер равен удвоенному диаметру анода. Если применить результаты анализа винтовой неустойчивости по модели дуги в трубке $[13,14]$, то двойной диаметр соответствует периоду винтовой структуры. Тогда с увеличением зазора (без увеличения) размера анода последовала бы винтовая неустойчивость. Однако пока наш механизм раздвижки электродов не позволяет получать стабильно выход на большие расстояния и нуждается в модернизации. Второй $(\sigma, s)$ режим привел к интенсивной эрозии анода, загрязнению и охлаждению разрядной плазмы с развитием сложных неоднородных плазменных структур, что и привело к погасанию дуги. 
В экспериментах с анодом вверху показано, что смена местоположения массивного анода усиливает эффект влияния скорости раздвижки на стабилизацию разряда. Это продемонстрировано ниже на рис. 4. и рис. 5 .

1

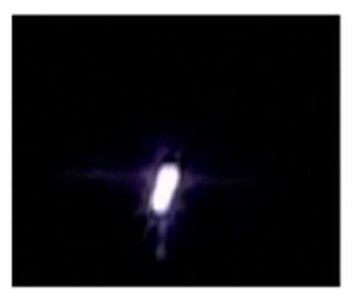

2

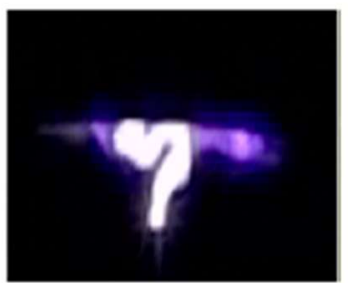

3

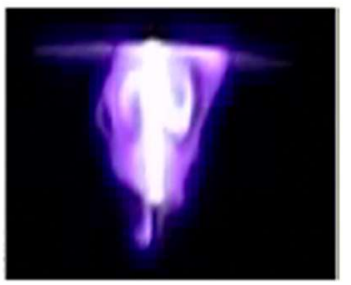

4

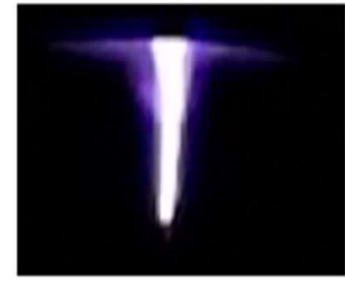

Рис. 4. Видеокадры по зонам 1-4 на рис. 5

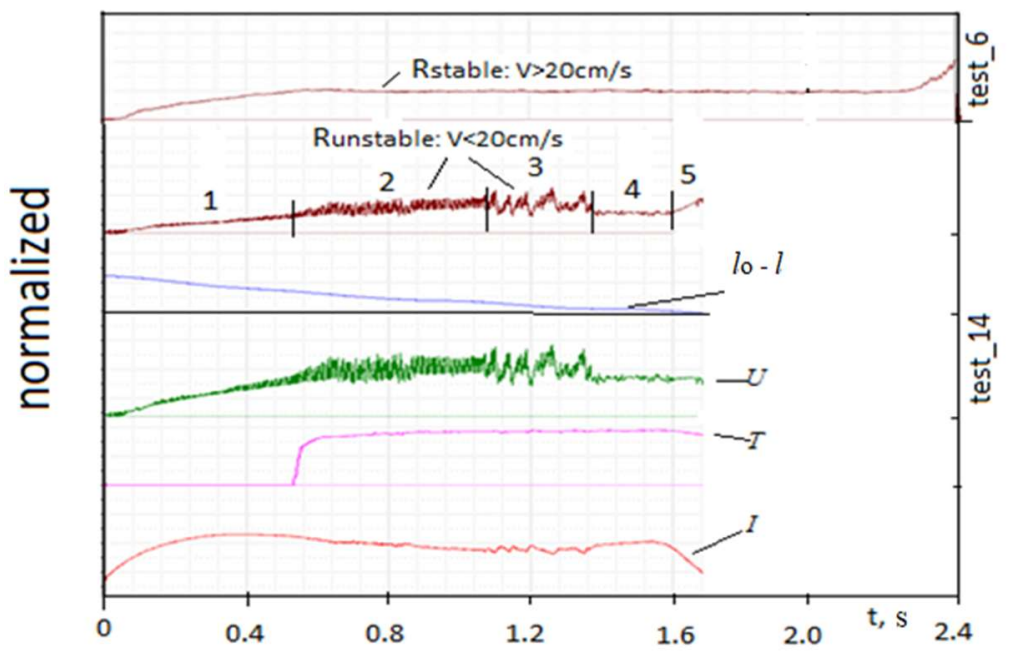

Рис. 5. Влияние скорости раздвижки на параметры и режимы разряда: 1 - устойчивая зона формирования дуг; 2,3 - зоны высокочастотной (кГц) и низкочастотной (десятки Гц) нестабильности; 4 - устойчивый разряд; 5 - выключение; параметры $R, I, U, T$ - сопротивление разряда, ток, напряжение, температура катода; $l_{0}, l$ - заданный зазор и переменное межэлектродное расстояние

\section{3. Спектральная диагностика межэлектродной среды при разных режимах раздвижки электродов}

Схема диагностики спектров и параметры спектрографа представлены на рис. 6. Измерения плотности электронов по штарковскому уширению линии $\mathrm{H}_{\beta}(485$ нм) [9] позволили оценить диапазон значений плотности электронов разрядной воздушной плазмы дуги атмосферного давления $N_{e}=1.7 \div 7.0 \times 10^{16} \mathrm{~cm}^{-3}$ (рис. 7).

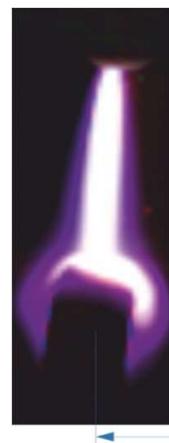

$\Delta x=1 \mathrm{~mm} f=75 \mathrm{~mm}$

$\Delta \mathrm{y}=8 \mathrm{MM}$

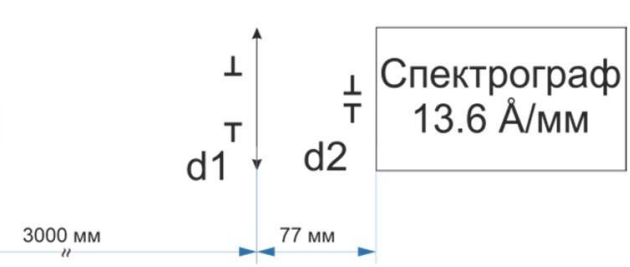

Рис. 6. Схема регистрации CCD линейкой с частотой 50 Гц, время экспозиции 10 мкс[8] 


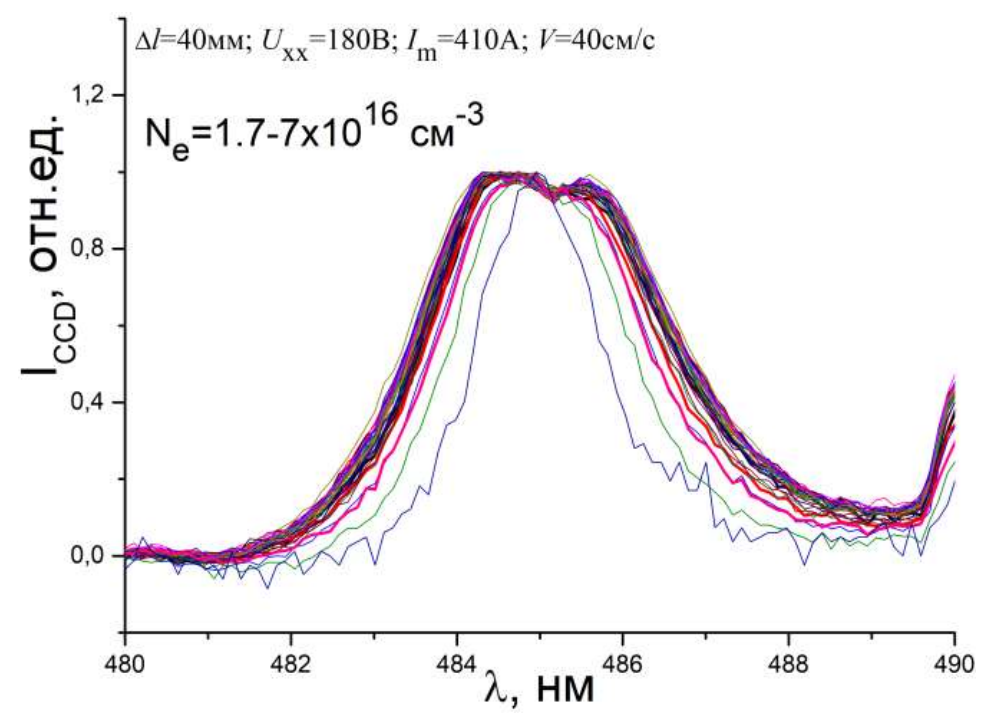

Рис. 7. Концентрация электронов: $l_{0}=40$ мм, напряжение холостого хода генератора $U_{\mathrm{xx}}=180 \mathrm{~B}, I_{m}=410 \mathrm{~A}, V=40 \mathrm{~cm} / \mathrm{c} ; \delta=10$ мм от анода; $N_{e}=1.7 \div 7 \times 10^{16} \mathrm{~cm}^{-3}$

Измерения в видимом диапазоне длин волн проведены при следующих условиях:

1. напряжение холостого хода $\left(U_{\mathrm{xx}}\right)$ источника питания разряда $180 \mathrm{~B}$;

2. межэлектродное расстояние $l_{0}=40 \mathrm{mм;}$

3. дисковый анод ( $\varnothing 150$ мм и толщиной $h=35$ мм) расположен внизу вертикального разряда;

4. стержневой (с полусферическим закруглением) анод ( $\varnothing 15$ мм) расположен вверху разрядного промежутка;

5. скорость раздвижения катода $V=40 \mathrm{mм} / \mathrm{c}$;

6. ток установившегося квазистационарного разряда менялся от 250 до 400 А (пусковой ток при инициировании разряда - 460 A);

7. время выхода разряда на квазистационарный режим (время раздвижки несколько меньше его) составило 0.2 с при общей продолжительности горения разряда - 1.5 с.

Динамика значений плотности электронов в измеренном диапазоне связана как с ростом или падением величины тока разряда, так и со временем прогрева материала электродов. В режиме стационарного горения разряда происходит насыщение величины электронной плотности на уровне $7.0 \times 10^{16} \mathrm{~cm}^{-3}$.

Рассмотрим изменение спектров излучения разрядной плазмы по зонам, центральной области столба дуги и области окрестностей электродов.

Центральную зону разряда характеризуют графики на рис. 8 и рис. 9, где приведены семейства спектров, снятых на оси разряда. При всем многообразии спектральных зависимостей в измеренном (видимом) диапазоне длин волн наблюдается схожая структура спектров излучения в окрестностях электродов, и общий характер динамики спектров со временем горения разряда. Особенно это проявляется у красной зоны изменения спектров.

Отметим, что дуговой разряд над плоским анодом формируется, в основном, катодной струей, падающей на анод. Поэтому схожие спектры у разнополярных электродов означают достаточно хорошее сохранение состава дуговой плазмы при её движении от катода к аноду.

В непосредственной близости от электродов (на меньших, чем указано выше расстояниях) спектральные кривые у разнополярных электродов могут существенно отличаться. Непосредственно в приэлектродных зонах наблюдается иная структура и динамика поведения в спектрах видимого излучения (рис. 10 и рис. 11). 


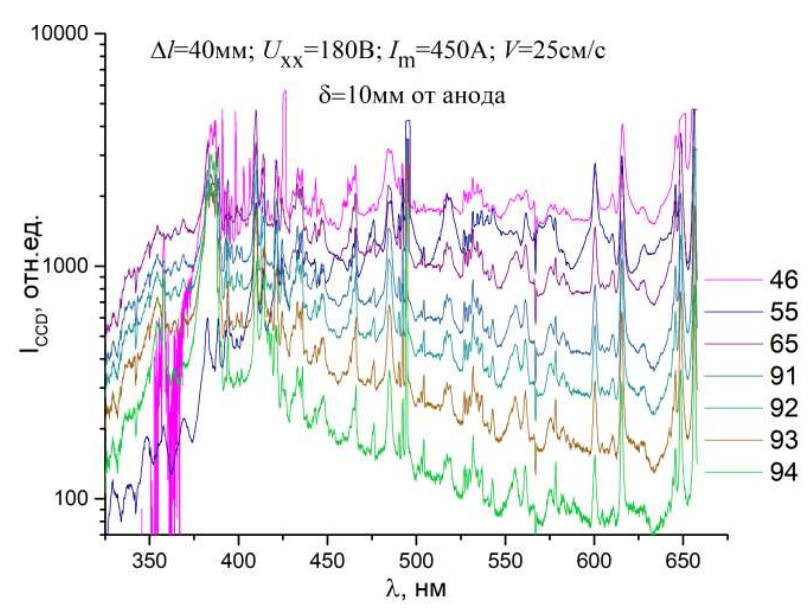

Рис. 8. Спектрограммы: $l_{0}=40$ мм, $U_{\mathrm{xx}}=180 \mathrm{~B}$, $I_{m}=450 \mathrm{~A}, V=25 \mathrm{~cm} / \mathrm{c}, \delta=10$ мм от анода

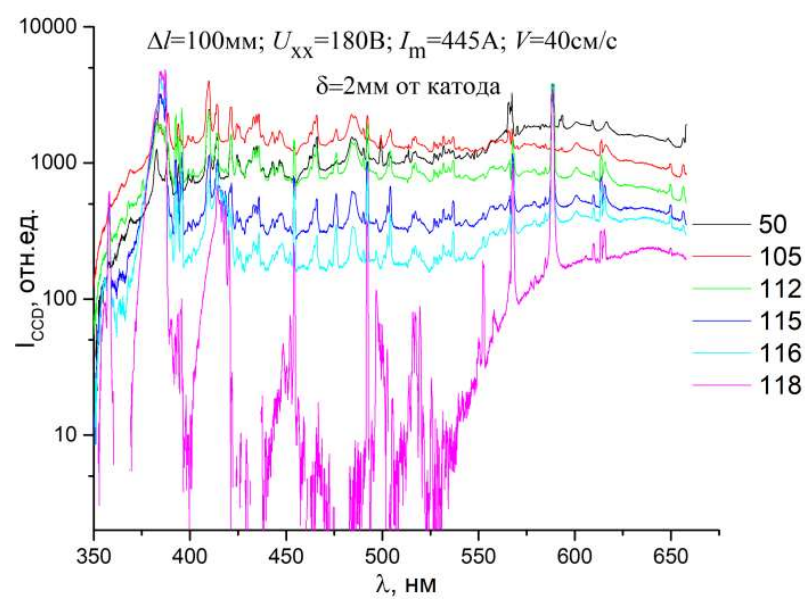

Рис. 10. Спектрограммы: $l_{0}=100 \mathrm{мm}, U_{\mathrm{xx}}=180 \mathrm{~B}$, $I_{m}=445 \mathrm{~A}, V=40 \mathrm{~cm} / \mathrm{c}, \delta=2$ мм от катода

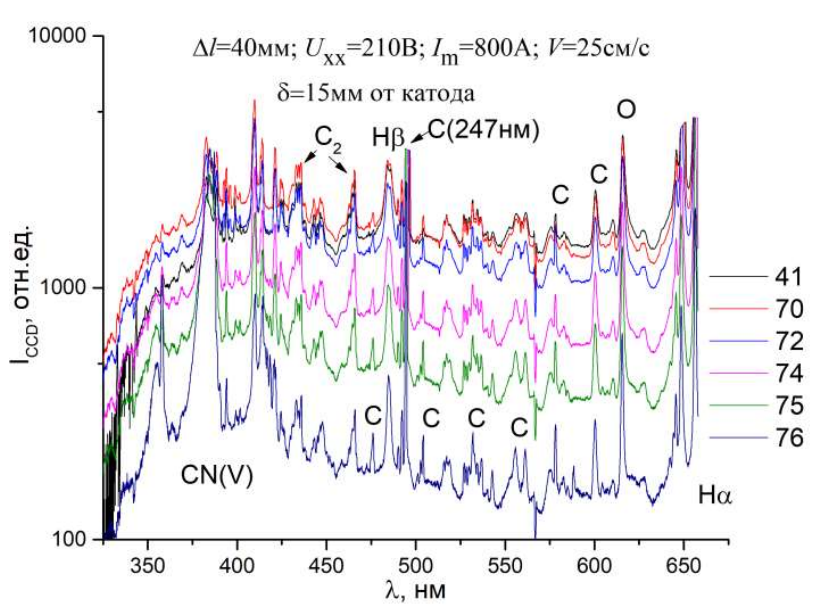

Рис. 9. Спектрограммы: $l_{0}=40$ мм, $U_{\mathrm{xx}}=210 \mathrm{~B}$, $I_{m}=800 \mathrm{~A}, V=25 \mathrm{~cm} / \mathrm{c}, \delta=15$ мм от катода

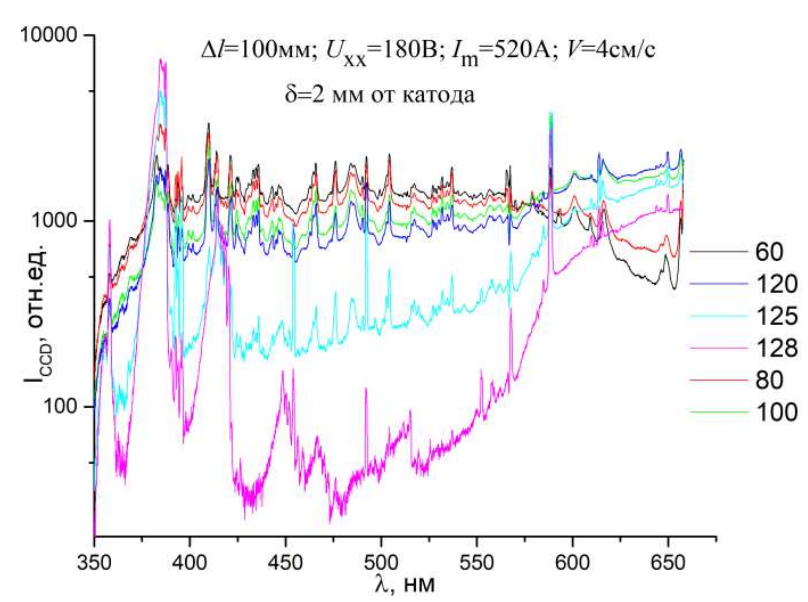

Рис. 11. Спектрограммы: $l_{0}=100$ мм, $U_{\mathrm{xx}}=180 \mathrm{~B}$, $I_{m}=520 \mathrm{~A}, V=4 \mathrm{~cm} / \mathrm{c}, \delta=2$ мм от катода

Во-первых, при инициировании разряда и его выходе на стационарный режим излучение, выходящее из прикатодной зоны (визирование производилось на расстоянии 2 мм от поверхности электрода в направлении по оси разряда), имеет более плавный спектр по сравнению со спектрами в положительном столбе разряда. Действительно, относительная интенсивность линий излучения становится существенно меньше на фоне сплошного спектра излучения.

Во-вторых, на красном крыле спектрального диапазона (650 нм) исчезают все линии излучения, зарегистрированные вдали от электрода.

В-третьих, на красном крыле спектрального диапазона происходит значительный рост уровня сплошного спектра излучения с возникновением его максимума в окрестности 600 нм.

Дальнейшее стационарное горение разряда приводит к значительному развитию относительного уровня излучения в этой зоне и смещению его максимума к 650 нм. При этом излучение в остальной части спектра (350-550 нм) резко дифференцируется. При сохранении интенсивностей нескольких линий излучения (CN, линия углерода 247 нм во втором порядке 494 нм и другие линии углерода) происходит падение уровня излучения во всем этом диапазоне на два порядка величины и более. Все это свидетельствует о значительной эрозии материала электрода при его разогреве разрядом. 
Особо следует подчеркнуть влияние скорости раздвижки электродов на интенсивность процесса эрозии электродов. Уменьшение скорости раздвижки электродов с 40 до $4 \mathrm{~cm} / \mathrm{c}$ приводит к росту уровня излучения в сплошной зоне красного крыла спектра на порядок величины.

Поскольку в спектрах излучения у поверхности электрода (катода) в конце пуска $(1.0 \div 1.5$ c) доминируют линии углерода $(\mathrm{C})$ и сплошной спектр в красном его крыле, то можно предположить о существенном наличии пылевой плазмы в этом режиме разряда. Такая плазма образуется при эрозии заряженных аэрозолей (частиц пыли) с раскаленного катода, и её динамика поведения может сильно отличаться от движения катодной струи в разряде.

\section{4. Заключение}

На электроразрядном стенде установки П-2000 НИИ механики МГУ реализованы режимы стабильного горения протяженной (до 30 см) сильноточной (до 700 А) стационарной электрической дуги в открытой воздушной среде. Результат получен без использования традиционных методов стабилизации: наложения внешнего магнитного поля, стабилизации изоляционными стенками или вихревого обжатия внешними потоками газов. Стабилизация обеспечивается за счет выбора материалов, оптимизации и согласования размеров и формы электродных узлов, и развития системы инициирования дуги с помощью раздвижки электродов при разных $(40 \div 400$ мм/с) скоростях их движения. Реализуется стабильная катодная струя, взаимодействующая не с твердой поверхностью анода, а с узким $(1 \div 2$ см $)$ прианодным плазменным слоем, формируемым анодными струйками, как из опорных пятен дуги, так и с горячей (до $1800^{\circ} \mathrm{C}$ ) поверхности анода [2-4]. Ранее плазменный (струйный) анод рассматривался в [10] при изучении прианодных неоднородностей разряда.

Экспериментально изучены процессы инициировании дуговых разрядов разведением при различных скоростях первоначально сомкнутых электродов. Исследовано влияние скорости раздвижки электродов на изменение резистивных и вольтамперных характеристик разряда и состав межэлектродной плазмы. В частности, существует диапазон скоростей раздвижки $(200 \div 300$ мм/с), при котором состав и параметры плазмы изменяются слабо. При малых скоростях раздвижки электродов разрядная плазма обогащается за счет эрозии материала электрода, что может приводить в отдельных случаях к уменьшению электрического сопротивления и увеличению разрядного тока на десятки процентов.

Полученные в настоящей работе результаты могут быть востребованы: в разработках систем инициирования и гашения протяженных электрических дуг; для моделирования испытаний защитных покрытий летательных аппаратов при их входе в плотные слои атмосферы планет, в частности Земли; при разработке установок утилизации (в т.ч. и токсичных) отходов, трудно разлагающихся при использовании традиционных химических технологий $[11,12]$.

\section{Благодарности и ссылки на гранты}

Авторы признательны профессору Г.А. Любимову за консультации и обсуждения при модернизации электроразрядного стенда на установке П-2000.

Работы проводились в НИИ механики МГУ имени М.В. Ломоносова по бюджетной теме AAAA-A16-116021110198-5 при частичной финансовой поддержке гранта РФФИ № 1829-21022.

\section{Литература}

1. German V.O., Glinov A.P., Golovin A.P., Kozlov P.V., and Lyubimov G.A. Some Features of Imaging of the Processes Occurring in an Extended Arc Discharge in Atmospheric Pressure Air // Plasma Physics Reports, 2013. Vol. 39. No. 13. Pp.1142-1148. 
2. Glinov A.P., Golovin A.P., Kozlov P.V., Shaleev K.V., Lyubimov G.A., «Study of arc discharges on the P-2000 facility» J. Phys.: Conf. Ser. 125001 2019. https://iopscience.iop.org/issue/1742-6596/1250/1

3. Глинов А.П., Головин А.П., Козлов П.В., Любимов Г.А., Шалеев К.В. Об устойчивости электрических дуг, инициируемых размыканием первоначально сомкнутых электродов // XII Bceроссийский съезд по фундаментальным проблемам теоретической и прикладной механики, Уфа, 19-24 августа 2019 г, Труды, Т. 2. С. 767-769.

4. Глинов А.П., Головин А.П., Козлов П.В., Шалеев К.В. Динамика формы электрической дуги и сопутствующих магнитогазодинамических течений, возникающих при размыкании изначально замкнутых электродов //Физико-химическая кинетика в газовой динамике. 2019. Т.20, вып.2. http://chemphys.edu.ru/issues/2019-20-2/articles/835/

5. Глинов А.П., Головин А.П., Шалеев К.В. Стенд для изучения процессов инициирования протяженных сильноточных разрядов // XLVII Международная Звенигородская конференция по физике плазмы и УТС, 16-20 марта 2020 г. ICPAF-2020. С. 203.

DOI:10.34854/ICPAF.2020.47.1.158

6. Bauchire J.M., Hong D., Rabat H. and Riquel G. Radiative Energy Measurements of Pulsed HighCurrent Arcs // The 20th Int. Symp. in Plasma Chemistry (ISPC), Philadelphia USA, July 24-29 2011, Paper 565.

7. German V.O., Glinov A.P., Kozlov P.V., and Lyubimov G.A. Spectral Properties of a Diffuse-Constricted Arc Discharge, High Temp. 50, 167 (2012).

8. Сайт ООО "МОРС" [Электронный ресурс]. - URL: http://www.ooo-mors.ru

9. Marco A. Gigosos, Manuel A. Gonzalez, Valentın Cardenoso. Computer simulated Balmer-alpha, beta and -gamma Stark line profiles for non-equilibrium plasmas diagnostics // Spectrochimica Acta Part B 58 (2003) 1489-1504.

10. Фахрутдинова И.Т., Гайсин Аз.Ф., Сон Э.Е., Галимзянов И.И., Гайсин Ф.М., Мирханов Д.Н. Об особенностях электрического разряда между струйным анодом и металлическим катодом // TBT, 2017, Т. 55, № 6, c. 775-777.

11. Васильева О.Б., Кумкова И.И., Рутберг А.Ф., Сафронов А.А., Ширяев В.Н., Возможности применения плазменных технологий для переработки органосодержащих веществ. Особенности процессов в дуговых камерах плазматронов //ТВТ, 2013, Т. 51, № 1, с. 36-40.

12. Рутберг А.Ф., Васильева О.Б., Кумкова И.И., Сафронов А.А., Возможности применения плазменных технологий для переработки органосодержащих веществ. Особенности сильноточных свободногорящих дуг //ТВТ, 2013, Т. 51, № 2, с. 191-197.

13. Недоспасов А.В., Хаит В.Д. Колебания и неустойчивости низкотемпературной плазмы. М: Наука, 1979.168 с.

14. Недоспасов А.В., Хаит В.Д. Основы физики процессов в устройствах с низкотемпературной плазмой. М.: Энергоатомиздат, 1991. 224 с.

\section{Reference}

1. German, V. O., Glinov, A. P., Golovin, A. P., Kozlov, P. V., and Lyubimov, G. A., "Some Features of Imaging of the Processes Occurring in an Extended Arc Discharge in Atmospheric Pressure Air," Plasma Physics Reports, Vol. 39, No. 13, 2013, pp.1142-1148.

2. Glinov, A. P., Golovin, A. P., Kozlov, P. V., Shaleev, K. V., Lyubimov, G. A., "Study of arc discharges on the P-2000 facility," J. Phys.: Conf. Ser., Vol.1250, No. 01, 2019. https://iopscience.iop.org/issue/1742-6596/1250/1

3. Glinov, A. P., Golovin, A. P., Kozlov, P. V., Ljubimov, G. A., Shaleev, K. V., "Ob ustojchivosti jelektricheskih dug, iniciiruemyh razmykaniem pervonachal'no somknutyh jelektrodov," XII Vserossijskij s\#ezd po fundamental'nym problemam teoreticheskoj i prikladnoj mehaniki, Ufa, Trudy, Vol. 2, Aug. 2019, pp. 767-769/ 
4. Glinov, A. P., Golovin, A. P., Kozlov, P. V., Shaleev, K. V., "Dinamika formy jelektricheskoj dugi i soputstvujushhih magnitogazodinamicheskih techenij, voznikajushhih pri razmykanii iznachal'no zamknutyh jelektrodov," Fiziko-himicheskaja kinetika v gazovoj dinamike (Physical-Chemical Kinetics in Gas Dynamics), Vol. 20, No. 2, 2019. http://chemphys.edu.ru/issues/2019-20-2/articles/835/

5. Glinov, A.P., Golovin, A.P., Shaleev, K.V., "Stend dlja izuchenija processov iniciirovanija protjazhennyh sil'notochnyh razrjadov," XLVII Mezhdunarodnaja Zvenigorodskaja konferencija po fizike plazmy i UTS, March 2020. ICPAF-2020. P. 203. DOI:10.34854/ICPAF.2020.47.1.158

6. Bauchire, J. M., Hong, D., Rabat, H. and Riquel, G., "Radiative Energy Measurements of Pulsed High-Current Arcs," The 20th Int. Symp. in Plasma Chemistry (ISPC), Philadelphia USA, July 24-29 2011, Paper 565.

7. German, V. O., Glinov, A. P., Kozlov, P. V., and Lyubimov, G. A., "Spectral Properties of a DiffuseConstricted Arc Discharge," High Temp., Vol. 50, No. 2, 2012, p. 167.

8. $\quad$ Sajt OOO "MORS" [Jelektronnyj resurs]. - URL: http://www.ooo-mors.ru

9. Gigosos, Marco A., Gonzalez, Manuel A., Cardenoso, Valentın, "Computer simulated Balmer-alpha, -beta and -gamma Stark line profiles for non-equilibrium plasmas diagnostics," Spectrochimica Acta Part B 58, 2003, pp. 1489-1504.

10. Fahrutdinova, I. T., Gajsin, Az. F., Son, Je. E., Galimzjanov, I. I., Gajsin, F. M., Mirhanov, D. N., "Ob osobennostjah jelektricheskogo razrjada mezhdu strujnym anodom i metallicheskim katodom," TVT, Vol. 55, No. 6, 2017, pp. 775-777.

11. Vasil'eva, O. B., Kumkova, I. I., Rutberg, A. F., Safronov, A. A., Shirjaev V.N., "Vozmozhnosti primenenija plazmennyh tehnologij dlja pererabotki organosoderzhashhih veshhestv. Osobennosti processov v dugovyh kamerah plazmatronov," TVT, Vol. 51, No. 1, 2013, pp. 36-40.

12. Rutberg, A. F., Vasil'eva, O. B., Kumkova, I. I., Safronov, A. A., "Vozmozhnosti primenenija plazmennyh tehnologij dlja pererabotki organosoderzhashhih veshhestv. Osobennosti sil'notochnyh svobodnogorjashhih dug," TVT, Vol. 51, No. 2, 2013, pp. 191-197.

13. Nedospasov, A. V., Hait, V. D. Kolebanija i neustojchivosti nizkotemperaturnoj plazmy, M: Nauka, 1979, $168 \mathrm{p}$.

14. Nedospasov, A. V., Hait, V. D. Osnovy fiziki processov v ustrojstvah s nizkotemperaturnoj plazmoj. M.: Jenergoatomizdat, 1991, 224 p.

Статья поступила в редакцию 2 декабря 2020 г. 